\title{
Microscope observation of cracks of clay
}

\author{
Chen Liang ${ }^{1}$, Yilin Gui ${ }^{1, *}$, Cees van der Land ${ }^{2}$ \\ ${ }^{1}$ Newcastle University, School of Engineering, Newcastle upon Tyne, United Kingdom \\ ${ }^{2}$ Newcastle University, School of Natural and Environmental Sciences, Newcastle upon Tyne, United Kingdom
}

\begin{abstract}
Clay has wide application in engineered barriers. However, it is prone to crack if moisture content decreases at most circumstances. This research aimed to microscopically study drying shrinkage and associated cracking of two different clays: kaolin and sodium-based bentonite, using optical microscopeLeica DM2700 M, under controlled condition. The samples used were cylindrical with $20 \mathrm{~mm}$ in diameter and $1 \mathrm{~mm}$ in depth. During the observation, microscopic images were captured and saved. These images were used to analyse the cracking behaviour due to drying. The testing results showed that cracks initially occur in the middle of the sample and then propagate to the sample boundary. The length and width of the crack was increased as moisture decreased.
\end{abstract}

\section{Introduction}

Due to the loss of excess moisture in the soil, desiccation cracks formed by restraint to volumetric changes and this is called drying shrinkage of soil. It is an important issue if desiccation cracks appeared in soil as the cracks affect the overall stability, reduce the bearing capacity of fractured soil, increase the compressibility of the soil which leads to cracking of the building [1-6].

Cracking is a complex process that has a great influence on the nature of the soil and plant growth. In recent year, extreme arid climates, such as the heatwave in the United Kingdom in 2018 have occurred frequently and cause large area of soil shrinkage. The shrinkage induced cracks in the Wayoh Reservoir near Manchester and March Haigh Reservoir near Huddersfield. The formation of cracks increases the evaporation of the water in the soil and affect the growth of vegetation. In slope engineering, the shrinkage cracks increase the permeability of the soil and reduces the strength and stability of the soil, which accelerates the weathering of the soil and exacerbates the soil erosion of the slope [7]. Rainwater seeps into the slope along the cracks and causes the landslide. In environmental engineering, the crack at the clay cover in landfill provides a fast track of migration of leachate, which poses a threat to groundwater and geological environment.

Researchers have studied many problems related to desiccation cracks in the past few decades, but so far, people have not found an effective solution to the problem of cracks, which involves the physical, chemical, mechanical, hydraulic parameters of the clay and also the surrounding environment. Currently, the most of the studies focus on observation of macroscopic cracks in clay. However, observing microscopic cracks in clay may have interesting findings.
In this paper, optical microscope is used to investigate two representative clay soils' response to desiccation. From the observation, the distinction between the two soils and the cracking velocity in each of the soil was obtained and compared.

\section{Experimental programme}

This experiment is aimed to provide qualitative information and quantitative data in desiccation cracking of two different clays: kaolin and sodium bentonite. The experimental apparatus includes: Leica DM2700 M microscope, microscope slide, electronic balance (accurate to $0.01 \mathrm{~g}$ ).

The original state of clay is powdery, so the test samples must be prepared before the observation under the microscope. Before preparing the sample, an Atterberg limits test was carried out to measure the plastic limit (PL) and liquid limit (LL) of the clays, in order to give the plasticity index (PI). Plasticity index can be found by using following equation:

$$
P I=\mathrm{LL}-\mathrm{PL}
$$

The tests are done in accordance with BS 1377-2:1990 [8]. The material properties of clays are shown in Table 1 .

In the laboratory, kaolin and bentonite powder are placed inside containers and mixed with a water content of approximately 55\% and $300 \%$ respectively. De-aired water is poured directly into the container and a palette knife was used for mixing water and clay. Then the clays are packed in sealed plastic bag and left for at least seven days to make sure the clays retain its moisture content and become homogenised.

\footnotetext{
$\overline{{ }^{*} \text { Corresponding author: yilin.gui@ncl.ac.uk }}$
} 
Table 1. Material properties of kaolin and bentonite

\begin{tabular}{|c|c|c|}
\hline Soil property & Bentonite & Kaolin \\
\hline Specific gravity & 2.6 & 2.6 \\
\hline Liquid Limit & $408 \%$ & $59.5 \%$ \\
\hline Plastic Limit & $39.3 \%$ & $31.9 \%$ \\
\hline Plasticity Index & $368.7 \%$ & $27.6 \%$ \\
\hline
\end{tabular}

Temperature and humidity are the important factors that significantly influence the desiccation process of the soil clay. In this study, the environmental conditions need to be kept constant to remove the influence of temperature and humidity. Therefore, all the experiments were carried out in the Geotechnical laboratory in the School of Engineering at Newcastle University. The samples are prepared indoors to prevent direct sun exposure on the soil surface. The samples were left under dry condition with room temperature between $22^{\circ} \mathrm{C}$ to $25^{\circ} \mathrm{C}$. The humidity remains constant during the preparation, approximately $40 \%$.

Images were obtained using a Leica Microsystems DM2700P microscope equipped with a Leica DEF450 C Digital Camera. The associated software package (Leica Application Suite) records the scale of the image which allows for direct length measurements on the produced image.

The observations of two-dimensional crack initiation and propagation were carried out on a microscope slide, approximately $10 \mathrm{~g}$ of each clay is placed on the microscope slides. The test samples were made into a cylindrical shape with a diameter of $20 \mathrm{~mm}$ and a depth of $1 \mathrm{~mm}$ as shown in Fig 1. A palette knife was used to make the sample surface as flat as possible so that the light is smooth and even for observation. The shape of the sample can help to minimise the boundary restraints which will influence the crack initiation and propagation significantly. The clays dried in a temperature-controlled room $\left(22^{\circ} \mathrm{C} \pm 1{ }^{\circ} \mathrm{C}\right)$. According to past experimental experience, the shrinkage of clay is evident at an early stage, so the weight of the clay is measured every 10 minutes until the shrinkage tends to stop.

When the sample was placed under the microscope, the live digital image is displayed on the PC monitor. The process of desiccation cracking typically lasts for several hours, especially for thick layers. In order to monitor the crack propagation and loss of water content, the samples were periodically photographed and weighted during desiccation. Photographs of the sample surface were taken and saved in the drive for further analysis.

\section{Results and discussion}

Figure 2 and 3 show that the crack development during the desiccation process of kaolin and bentonite under optical microscope, respectively. An enlarged version with scale for Fig. 2 and 3 is presented in Fig. A1 and A2. There is a tiny crack initiated at the upper right corner for the kaolin (Fig. 2a) at 28 minutes after desiccation and, then the crack propagates in a direction approximately $45^{\circ}$ to the southwest in the microscopic field of vision. In the end of the desiccation, the desiccation crack propagate across the observation area along southwest. As the time elipse, the length and width of the crack become larger. An larged photo of Fig. 2d is presented in Fig. A1.

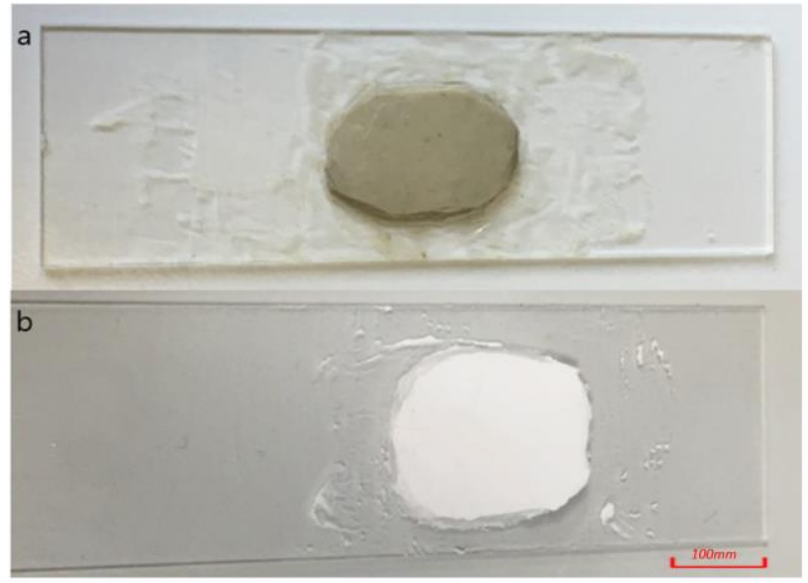

Fig. 1. Prepared clay samples on glass slide; a) bentonite b) kaolin (samples are approximately $20 \mathrm{~mm}$ in diameter).

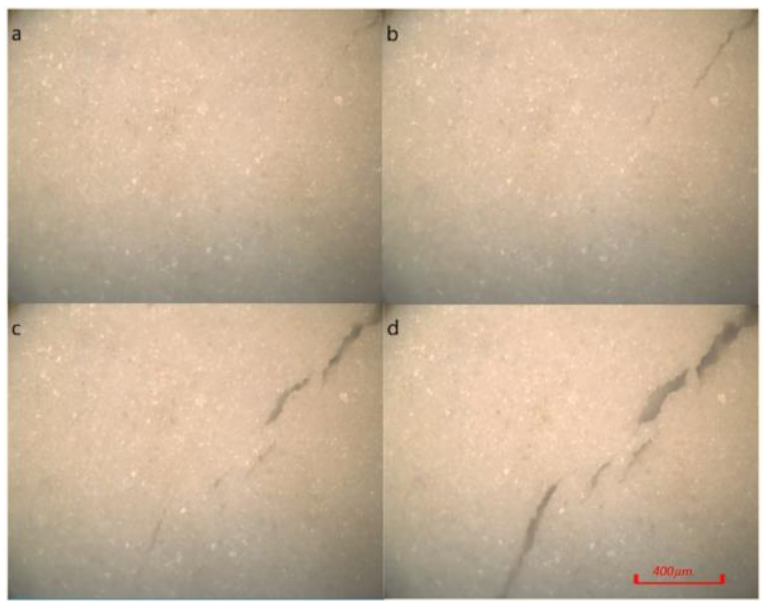

Fig. 2. Observation of crack propagation in kaolin at a) 28 minutes, b) 31 minutes, c) 41 minutes, d) 81 minutes

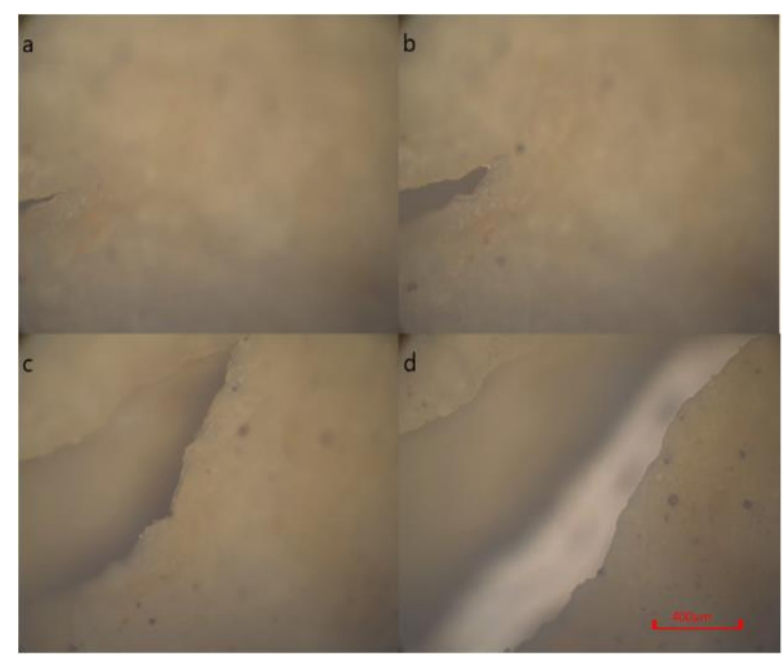

Fig. 3. Observation of crack propagation in bentonite at a) 23 minutes, b) 38 minutes, c) 105 minutes, d) 161 minutes

In Fig. 3(a), the initial crack in bentonite appears in the middle of the left edge started after 23 minutes desiccation Conversely, the crack propagates in a direction 
approximately $45^{\circ}$ to the north-east. Cracking is very significant aross the observation field. It is clearly shown that the bentonite has a larger size of cracking than kaolin (Fig. A1 and A2).

Bentonite has been tested in the Atterberg test that result shows bentonite has nearly $360 \%$ of plasticity index (PI), which is much higher than that of kaolin. This means bentonite has high plasticity.

Figure 4 and 5 shows a cracking propagation comparison of length and width in bentonite and kaolin, respectively. In bentonite, the propagation of the length stops after 105 minutes from the beginning, this is due to the beyond of the observation field. The camera under the optical microscope can only view an image size of $1583 \times 1181 \mu \mathrm{m}(\approx 1.6 \mathrm{~mm} \times 1.2 \mathrm{~mm})$, any changes outside the observation range cannot be discovered. In kaolin, the length propagation stops at 70 minutes.

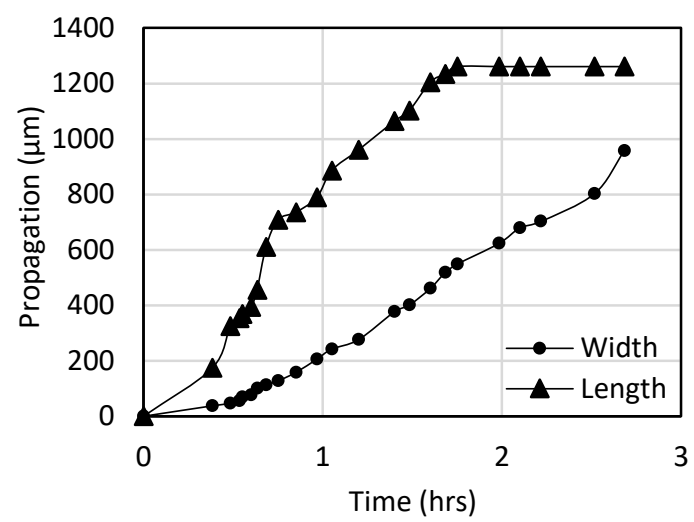

Fig. 4. Width and length propagation over time in bentonite

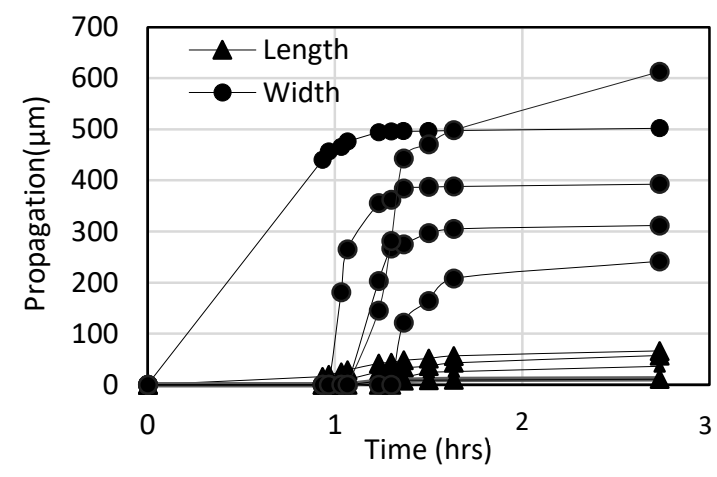

Fig. 5. Width and length propagation over time in kaolin

Figure 6 shows the moisture evolution over time for both kaolin and bentonite. The linear curves contain two stages, the first stage was from the start to 6 hours, the second stage was after 6 hours time. The deep slope happens in first stage, then the slope become steady in second stage. The results indicate that moisture content decrease with time due to desiccation, which matches the result of [2].

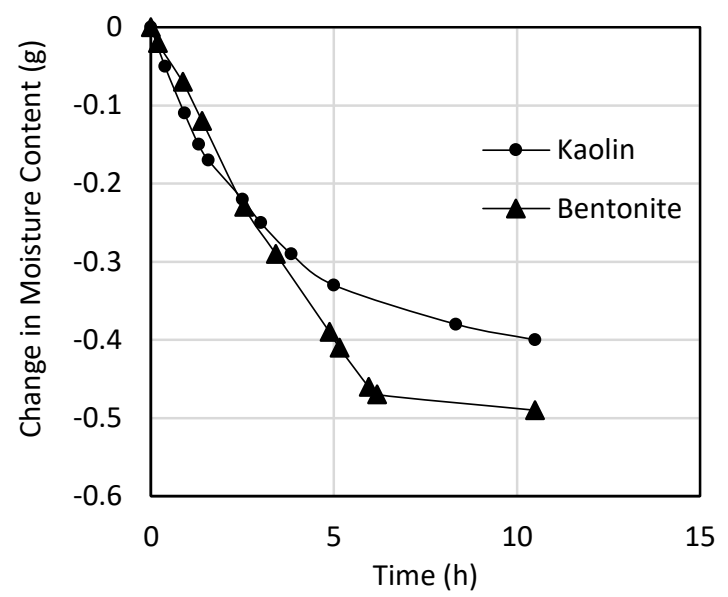

Fig. 6. Moisture change in kaolin and bentonite

From Fig. 5, the moisture content of kaolin and bentonite is reduced by a total of $6.3 \%$ and $8.4 \%$ respectively. The comparison between kaolin and bentonite indicates that bentonite has a higher moisture loss rate than kaolin, therefore bentonite needs more time for water evaporate in the air. Bentonite loses a large amount of water in a short time, this is due to its excellent absorption performance, bentonite can absorb as much water as several times its dry mass. Due to the limitation of experimental time, the moisture content of bentonite was only reduced by $8.4 \%$, which is far lower than expected as the bentonite has a liquid limit of $390 \%$. The kaolin can be dried in a short time and with little shrinks. The bentonite has such a high hygroscopy for water that it may take a week to dry the sample, which can reduce to half the original size.

\section{Conclusion}

A study of desiccation crack in kaolin and bentonite with microscope experiment is presented in this paper. The characteristics of kaolin and bentonite during desiccation are identified by using image analysis, which obtained from the optical microscope.

The micro crack propagation of kaolin and bentonite was determined in this study. The crack initiated in the centre of the two clay samples and propagate toward the edge. The initial crack of bentonite occurs at 23 minutes after the beginning and propagate $45^{\circ}$ to the south east. The initail crack of kaolin occurs at 28 minutes after the beginning and propagate approximately $45^{\circ}$ to the north east.

Length and width of the crack during different time period also determined. The results of crack propagation has been analyzed and explained. After the initial crack apperaed, the length and width of the cracks increases over time. Bentonite has a significant change in width and length than kaolin:

- The maximum length propagation in kaolin and bentonite was $612 \mu \mathrm{m}$ and $1260 \mu \mathrm{m}$ respectively.

- The maximum width propagation in kaolin and bentonite was $66 \mu \mathrm{m}$ and $958 \mu \mathrm{m}$ respectively 
The cracking of kaolin stopped extending in the middle of the experiment, but the cracking of bentonite continued extending until the end of the experiment.

Due to its high plasticity, bentonite shrink a lot and causes cracks to be larger than kaolin and also more cracks than kaolin.

The moisture content at the different time period in kaolin and bentonite were identified:

- The moisture content of kaolin has an initial weight of $6.32 \mathrm{~g}$, and a weight of $5.92 \mathrm{~g}$ at the end of the experiment.

- The moisture content of bentonite has an initial weight of $5.82 \mathrm{~g}$, and a weight of $5.33 \mathrm{~g}$ at the end of the experiment.

The moisture content decrease with time. Kaolin become dry in a short time and shrinks very little. Bentonite uses twice as much time to dry than kaolin and shrinks a lot. Both the clay samples shrink in all directions (length, width, depth).

\section{References}

1. C.J.Miller, H. Mi, N. Yesiller. Experimental analysis of desiccation crack propagation in clay liners. J Am Water Resour Assoc. 34(1998):677-686.

2. Y.L.Gui, G. Zhao, N. Khalili. Experimental investigation of desiccation of clayey soils. 22th Australasian Conference on the Mechanics of Structure and Materials. Sydney Australia 2012.

3. Y. Gui, G.F.Zhao, N.Khalili. Numerical investigation of desiccation cracking in fine-grained soil using a lattice spring model. International Conference on Unsaturated Soils. Sydney, Australia. 2014.

4. Y.Gui, G.F.Zhao. Modelling of laboratory soil desiccation cracking using DLSM with a two-phase bond model. Comput. Geotech. 69(2015): 578-587.

5. Y.L. Gui, Z.Y.Zhao, J.Kodikara, H.H.Bui, S.Q.Yang. Numerical modelling of laboratory soil desiccation cracking using UDEC with a mix-mode cohesive fracture model. Eng. Geol. 202(2016): 14-23.

6. Y.L. Gui, W. Hu, Z.Y.Zhao, X.Zhu. Numerical modelling of a field soil desiccation test using a cohesive fracture model with Voronoi tessellations. Acta Geotech. 13(2018):87-102.

7. H. Peron, T. Hueckel, L. Laloui, L.B. Hu. Fundamentals of desiccation cracking of fine-grained soils: experimental characterisation and mechanism identification. Can. Geotech. J. 46(2009):1177-1201.

8. BS 1377-2:1990. Methods of test for soils for civil engineering purposes - Part 2: Classification tests. 


\section{Annex}

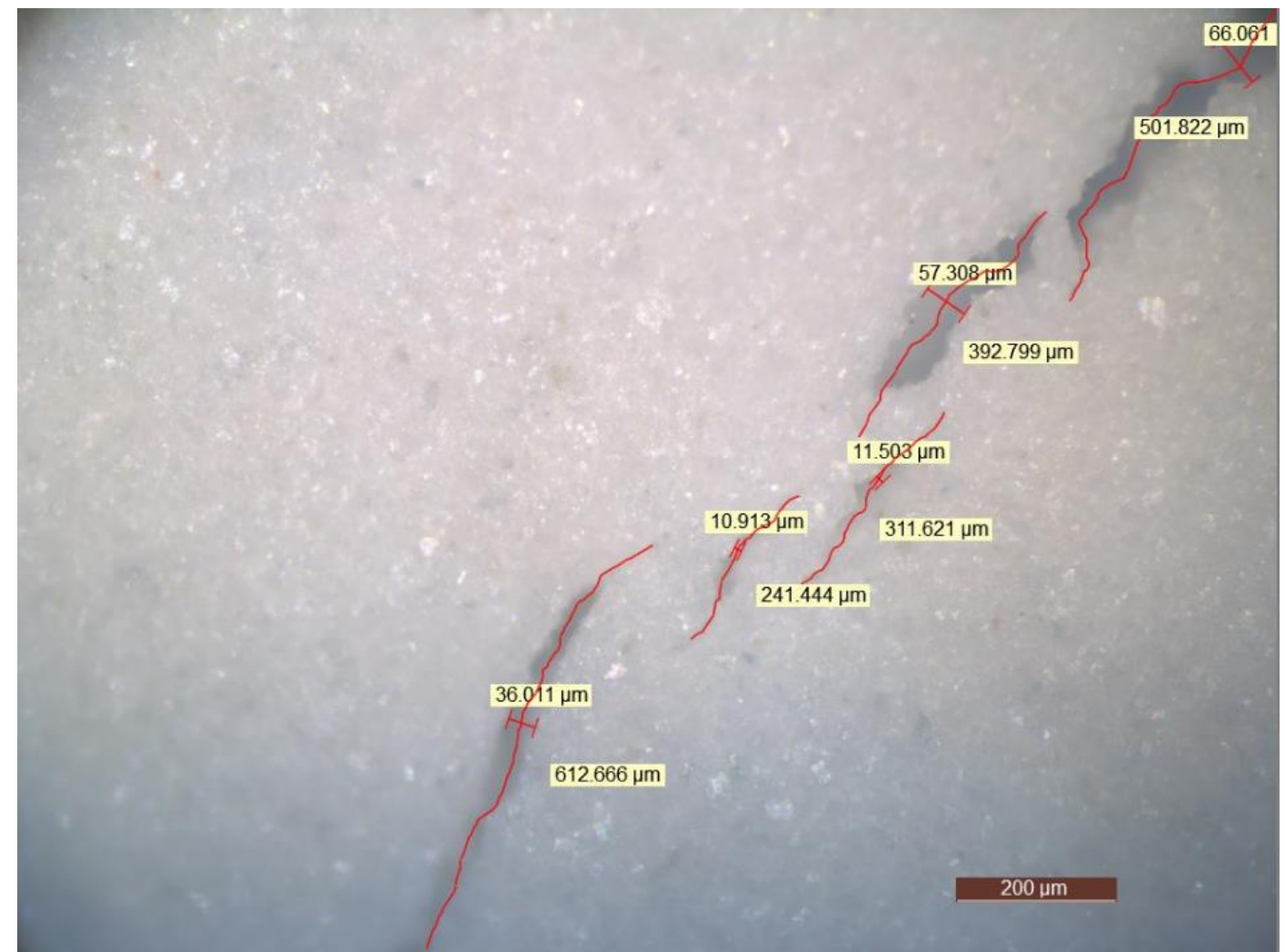

Fig. A1. Enlarged photo for Fig. 2(d).

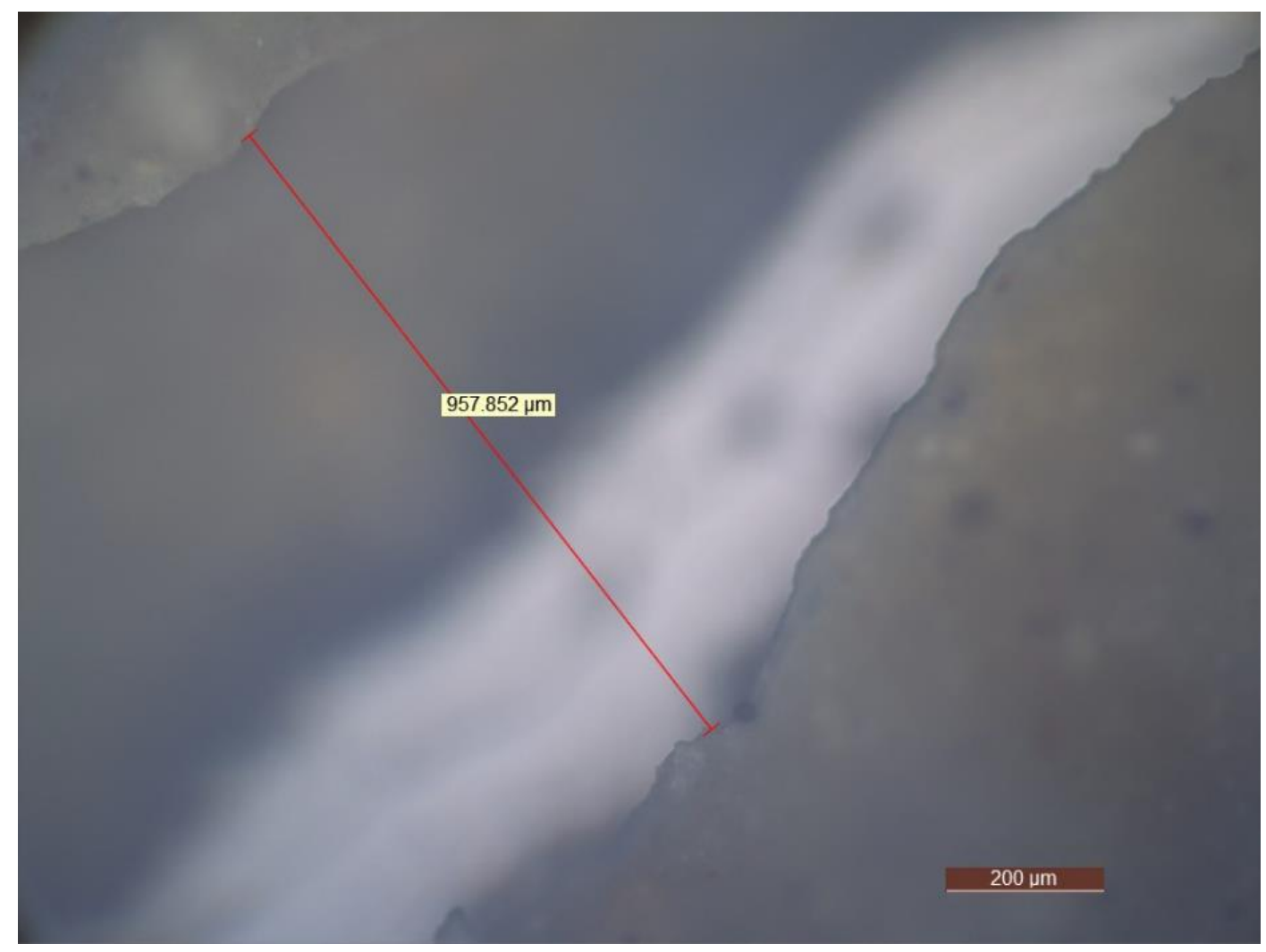

Fig. A2. Enlarged photo for Fig. 3(d). 